\title{
REVIEW
}

\section{Clinical review: The role of the intensivist and the rapid response team in nosocomial end-of-life care}

Andrew K Hilton', Daryl Jones',2 and Rinaldo Bellomo*1,2

\begin{abstract}
In-hospital end-of-life care outside the ICU is a new and increasing aspect of practice for intensive care physicians in countries where rapid response teams have been introduced. As more of these patients die from withdrawal or withholding of artificial life support, determining whether a patient is dying or not has become as important to intensivists as the management of organ support therapy itself. Intensivists have now moved to making such decisions in hospital wards outside the boundaries of their usual closely monitored environment. This strategic change may cause concern to some intensivists; however, as custodians of the highest technology area in the hospital, intensivists are by necessity involved in such processes. Now, more than ever before, intensive care clinicians must consider the usefulness of key concepts surrounding nosocomial death and dying and the importance and value of making a formal diagnosis of dying in the wards. In this article, we assess the conceptual background, reference points, challenges and implications of these emerging aspects of intensive care medicine.
\end{abstract}

\section{Introduction}

Life-support technology has profoundly changed medicine and has contributed to improved life expectancy in resource-rich nations. However, the technology has also substantially affected the circumstances, mode and timing of death in such societies. In this context, cessation of breathing or of the heartbeat no longer necessarily signifies the arrival of death [1] because doctors can substitute these vital functions with artificial

\footnotetext{
*Correspondence: Rinaldo.bellomo@austin.org.au

${ }^{2}$ Australian and New Zealand Intensive Care - Research Centre, School of Public Health and Preventive Medicine, Monash University, Alfred Hospital Campus, Commercial Road, Prahran, Victoria 3181, Australia

Full list of author information is available at the end of the article
}

organ supports in patients who would otherwise rapidly die without them. Such technology may facilitate recovery, and is therefore of potential benefit to the individual. In a significant proportion of cases, however, artificial life support will not confer an enduring benefit to the patient and will be associated with physical, emotional, spiritual and financial burdens to patients, their families and society [2].

Owing to the uncertainty of predicting death at the onset of clinical deterioration, a proportion of ICU admissions inevitably involve patients who receive artificial life support, only to die despite provision of such support, or, more often, only able to die when these are removed. In this environment, death may then become a programmed or orchestrated event, where the custodians of life-support technology may substantially influence when and how death will happen [3,4]. The management of dying and the provision of nasocomial end-of-life care (EOLC) have become ubiquitous and intrinsic to the daily practice of intensivists.

Furthermore, because the intensivist's role has also recently expanded to that of rapid response team (RRT) leader $[5,6]$, EOLC decisions are frequently made out of hours in a limited amount of time, in a non-ICU environment, in patients with whom the intensivist may not be familiar and with limited documentation of advanced care planning (Figure 1). In this article, we review and discuss the characteristics, conceptual and ethical implications, and practical consequences of the rapidly expanding developments of RRTs [5,7-17] in the practice of this aspect of intensive care medicine.

\section{End-of-life care and intensivists}

There are several reasons why intensivists are in a unique position to improve nosocomial EOLC. Intensive care physicians have a detailed understanding of key aspects of critical illness and limits of vital organ support. Independent of the patient's admission diagnosis ICU physicians also take into account the effect of specific physiological derangements on the probability of survival. Prognosis based on severity of organ dysfunction may differ substantially from that attributed to the admission diagnosis alone. Finally, intensive care physicians 


\section{Patient and family attitudes and perceptions of end of life care}

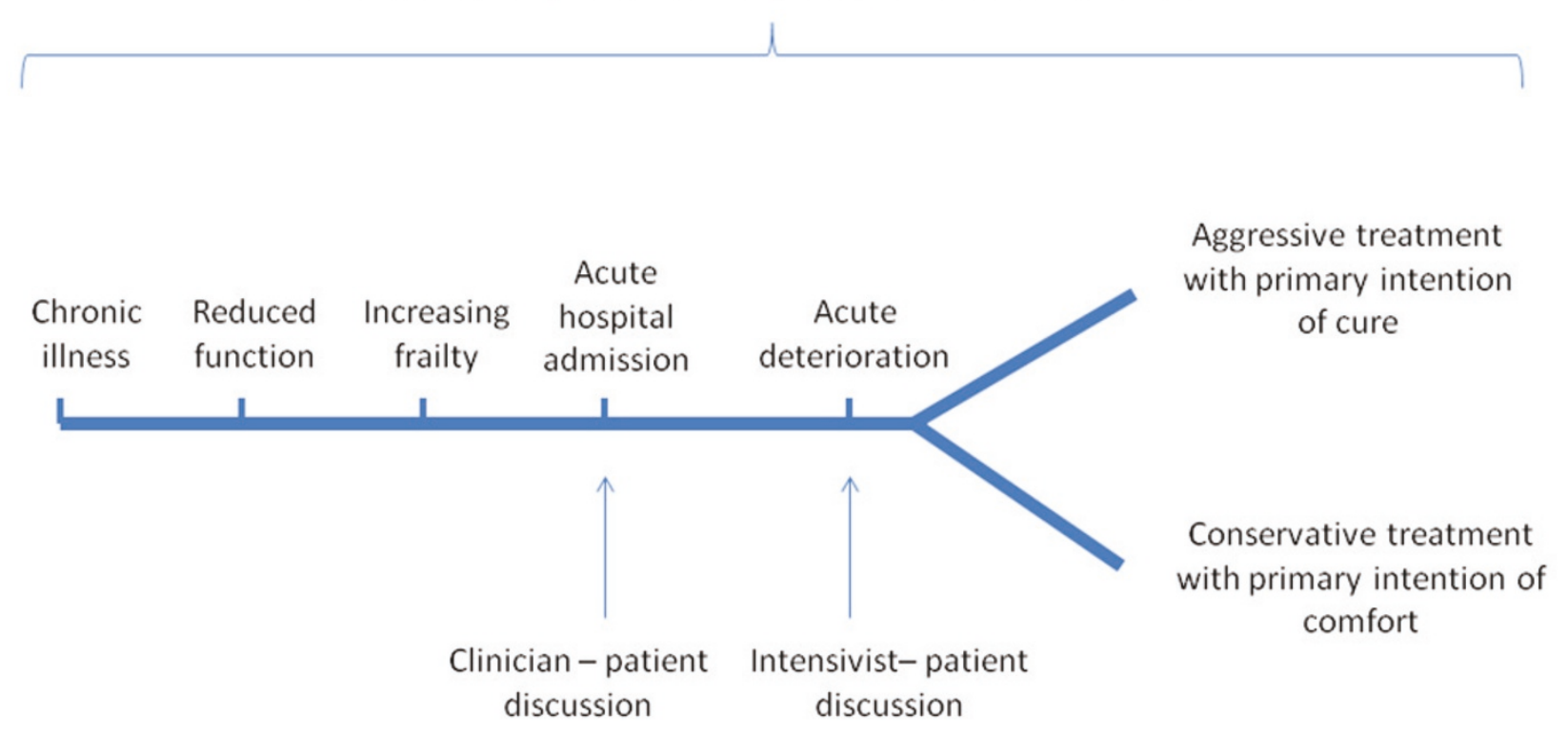

\section{Time}

Figure 1. Key aspects in the evolution of decision-making in relation to nosocomial end-of-life situations. Patients with chronic illness have reduced function and increasing frailty, which increase their risk of a crisis. This leads to hospital admission. As this happens, family observation of the patient's physical changes has an effect on their attitudes and perceptions of what might be desirable in terms of medical intervention. While in hospital with an acute admission, discussions with the clinician may also shape decision-making. An acute deterioration then leads to intensivist involvement and, in the absence of a clear documented plan, a partly informed semi-urgent or urgent decision has to be made to either pursue aggressive treatment or comfort treatment alone.

are in a position to explain to patients and families what the limits of the technology of life support might be in a specific clinical situation. Intensive care physicians can thus guide colleagues, patients and their families to an informed shared decision regarding the clinical utility and limits of artificial organ supports.

Similarly, there are several reasons why non-ICU physicians may be less favorably positioned to optimally deliver nosocomial EOLC in the critically ill. First, the ability of non-ICU physicians to prognosticate in cases of advanced disease has been reported to be poor and typically overly optimistic [18-20]. Second, as the task of providing care to critically ill patients shifts to the ICU team, primary physicians may only see such patients for a limited period of time during each day. This may impair their ability to make a fully informed judgment on their patients' condition and their appreciation of the degree of discomfort, loss of dignity and family distress being experienced while treatment is continued. Finally, nonICU physicians are less frequently exposed to EOLC decisions in a high-technology environment and typically find conversations with families in this setting difficult $[21,22]$.
The above differences between ICU and non-ICU physicians are made more relevant by recent developments in healthcare. In particular, an increasing proportion of deaths are happening in hospitals rather than at home. Furthermore, within the hospital, an increasing proportion of deaths occur in the ICU instead of on the general wards [23-31], perhaps as a consequence of the greater use of technology-based interventions. Finally, the introduction of RRTs has resulted in an increased involvement of ICU physicians in the care of dying ward patients $[5,8,9]$.

The intensive care physician's unique skills, experience and knowledge of advanced organ support technology has increased their involvement in managing acutely deteriorating ward patients. Consequently, they are now making more frequent and often difficult decisions about who should receive treatment escalation and who should receive EOLC in the wards. Such concerns necessitate that all clinicians ought to reflect more deeply on the concept of death and its management; the uncertainties surrounding the concept of and the differential diagnosis of dying; the management of these issues within the context of RRT calls; and the future role of intensive care medicine in these processes. 


\section{Diagnosing and defining nosocomial death: basic concepts}

Diagnosing death is the final step in the provision of EOLC. However, a universally applicable and acceptable definition of death remains elusive [32,33]. Scientific or philosophic responses to this problem often propose a functional definition: an organism is dead when its integrative and homeostatic functions are irreversibly lost [32]. Although such a definition appears intuitive, it presents a number of problems.

First, it is not possible to generally define a level of irreversible functional loss that constitutes death in all species. For example, what defines death in a jellyfish and in a human is profoundly different.

Second, until recently humans have been deemed dead solely on cardiorespiratory criteria - loss of the flow of blood in the circulation or air in the lungs $[1,32,33]$. Unresponsive loss of consciousness was a recognized associated sign, but cardiopulmonary criteria remained primary. The irreversible loss of all three of these key physiologic functions has been, and continues to be, used to define the moment of death at an earlier time than the late confirmatory signs of bodily decomposition. However, intrinsic irreversible loss of cardiorespiratory function can be replaced by technological supports. In the nosocomial environment, therefore, diagnosis of death can be deferred by a medical decision to externally support cardiorespiratory function. In other words, a medical decision regarding whether to intervene in a deteriorating patient directly impacts on the diagnosis of death [30-33].

The third problem with applying a universal definition of death is that humans also function within social, cultural, religious and economic domains. Death not only coincides with a significant change in biological function, but is also a marker of change in an individual's moral, social, spiritual, political, legal and economic status within society. It is at this point that the individual's moral rights are lost; it becomes acceptable for friends and relatives to mourn, organize funerals, pray for the soul of the deceased; corporate or political successions occur; and wills are read and inheritances are distributed. Accordingly, a definition of death is accepted not only because it conforms to contemporary understanding of biology, but also because it is consistent with the cultural, social, political norms and exigencies of that period. For example, while a definition of death based on the cessation of cardiorespiratory function has biologic plausibility, it is similarly coherent with a western cultural construct based on Christian view that the cessation blood flow and associated unresponsiveness identify the moment at which the soul leaves the body.

In summary, a definition of death allows, justifies or legalizes important medical and nonmedical practices.
The definition must both encompass and be coherent with medical diagnostic and technical capability and practice; and societal norms, values and expectations.

This historical and cultural contingency in the definition of death is exemplified in the evolution of the concept of brain death. Catastrophic brain injury remains technologically irreplaceable in itself, but for over 40 years it has been possible to provide and continue cardio-respiratory support almost indefinitely. Logically, in such cases, the patient cannot be declared dead by applying cardio-respiratory criteria even though independent existence without cardio-respiratory support would be impossible. The medical, social and legal ramifications of this problem lead to the concept of brain death. Irreversible loss of consciousness, brain stem reflexes and spontaneous breathing have all become accepted criteria for death in many countries $[1,31,33]$. This advance also coincided with the development of solid organ transplantation - an endeavor with wide social, political and legal endorsement, and which is technically and ethically facilitated by using donors declared dead on neurologic criteria.

Most patients who die in the ICU satisfy cardiorespiratory criteria for the diagnosis of death, but only a minority of these deaths occurs despite the presence of maximal vital organ support. Most patients die because vital organ supports are withheld or withdrawn. This practice is justified if providing organ support is not likely to confer an enduring important functional or mortality benefit, or if future independence from such supports is deemed improbable, with inevitable death from treatmentassociated complications. If despite these considerations there is no decision to withdrawal life-support technology the patient may be perceived as "dying" yet unable to die.

Unfortunately, individual prognostication of patients who appear to be dependent on life support is imprecise and the recognition that a patient is dying when organ support technology is either available or in place can be difficult and controversial. Importantly, when such support is in place it may retard, obviate or indeed obfuscate the cascade of inevitable vital organ failures that would result from severe injury or illness. Accordingly, a decision to withdraw or withhold further organ supports is both a medically informed decision and a negotiated act following discussion with family and other health providers [27-31]. When the decision to remove organ supports is accepted by all, the time and manner of death is determined and controlled by the orchestrated withdrawal of organ supports [27-31]. Sometimes, especially when there is controversy, orchestration necessitates gradual and sequential removal of organ supports in order to unmask the severity of underlying organ dysfunction, making this obvious to all those involved in 
the patient's care; and to allow a time and manner of death acceptable to the patient and family.

In some cases, orchestrated withdrawal of organ support facilitates potential organ donation after cardiorespiratory death [1]. In this setting, the timing of withdrawal is not decided by family and physician exigencies alone, but also by the logistics of organ procurement, and recipient availability and suitability [1].

Most nosocomial deaths occur on the wards and in the absence of ICU organ support [34-39]. Death outside the ICU may simply be allowed in a patient who is deemed to have an irreversible terminal disease process or injury that would not be preventable with ICU or non-ICU treatment. For others, although ICU admission is deemed inappropriate, active ward-based therapeutic intervention is continued - possibly delaying death but not preventing it. In either case, the timing and manner of death will be affected by the treatments that are continued and by if and when palliative care is provided.

In the ICU or on the wards, doctors can substantially influence if and when death will occur, as well as the type and manner of death. Interventions to immediately prevent death are justified by providing a possible cure (irrespective of this probability) or (less commonly) by deferring and transforming an expected death to a time and mode that facilitates potential organ donation. If and when such interventions should occur and the objective of these interventions are contingent on whether death is deemed soon and inevitable. This requires the recognition that the patient is dying, consensus as to this determination, and whether organ donation is being considered.

Several difficulties remain, however: the failure to recognize or have a consensus that a patient is dying; the failure to have clear decisions or understanding regarding ICU treatment; and the continuation of ineffective active treatment without effective palliative care $[40,41]$. These difficulties predispose the patient to continual suffering that only ends following an "unexpected" death, a death that may involve the indignity of futile cardio-respiratory resuscitation. A crucial issue must therefore be considered: the need to correctly determine whether dying is the primary relevant diagnosis.

\section{The primary diagnosis of dying}

The dying process can be interrupted at any stage of its development by the application of technology, thus masking a primary overarching diagnosis that the patient is dying. Consider the following example.

An 80-year-old patient with Alzheimer's disease just coping at home with his wife's assistance presents with pneumonia, septic shock and renal failure following a fractured neck of femur following a fall at home. This patient could be considered to have sepsis-induced multiple organ dysfunction syndrome necessitating vasoactive medications, renal replacement therapy and mechanical ventilation. Conversely, this frail patient with dementia could simply be considered as having the primary diagnosis of dying. Therapeutic interventions may postpone death but not prevent it. Even if short term ICU survival is achieved it will be followed by increased risk of hospital mortality, and further functional disability and loss of independence necessitating discharge to nursing home care. This poorer quality of life will precede a probable death within 12 months (Figure 2). In this setting, the diagnosis of dying should be seriously considered in hierarchical preference to that of septic shock due to the presence of chronic, cognitive decline and probable outcome trajectory. The patient still has septic shock with multiple organ failure, and dementia is not a direct contributor to this state. However, in this context although ICU survival is possible, the probability of an enduring survival benefit, and functional recovery with an acceptable quality of life is very small. Furthermore, cognitive decline might render any benefit unrealisable to the patient, but would not preclude the possibility of suffering. The primary and relevant diagnosis of dying would thus be justified and management should center on discussing such issues with the family and the primary clinician and recommending compassionate EOLC.

This approach would be completely different from that applied to a person with the same physical conditions of pneumonia, septic shock and renal failure following a fractured neck of femur from a motorbike accident in a 40-year-old man (Figure 3). In such a person, given the expected survival and functional recovery trajectory after critical illness, the diagnosis of dying appears much less likely, and advanced organ support technology should be initially applied.

Diagnosing dying is much more complex than the normal diagnosis of disease (whether the patient does or does not have a fractured neck of femur complicated by pneumonia and septic shock), where the only immediately relevant dimension is medical. The elevation of dying to the primary position in the hierarchy of patient diagnoses is a medically informed, technology-mediated, social decision.

The primary diagnosis of dying should be formally considered in the differential diagnostic list of all patients who present with severe illness and injury, especially but not exclusively patients with multiple co-morbidities, advanced age or poor physical performance, although its recognition will be influenced by the social context. The epidemiology of dying in hospitals from different countries reveals these social, cultural and resourcerelated dimensions. In the USA a significant proportion of hospital deaths occurs in the ICU [24-26], indicating 


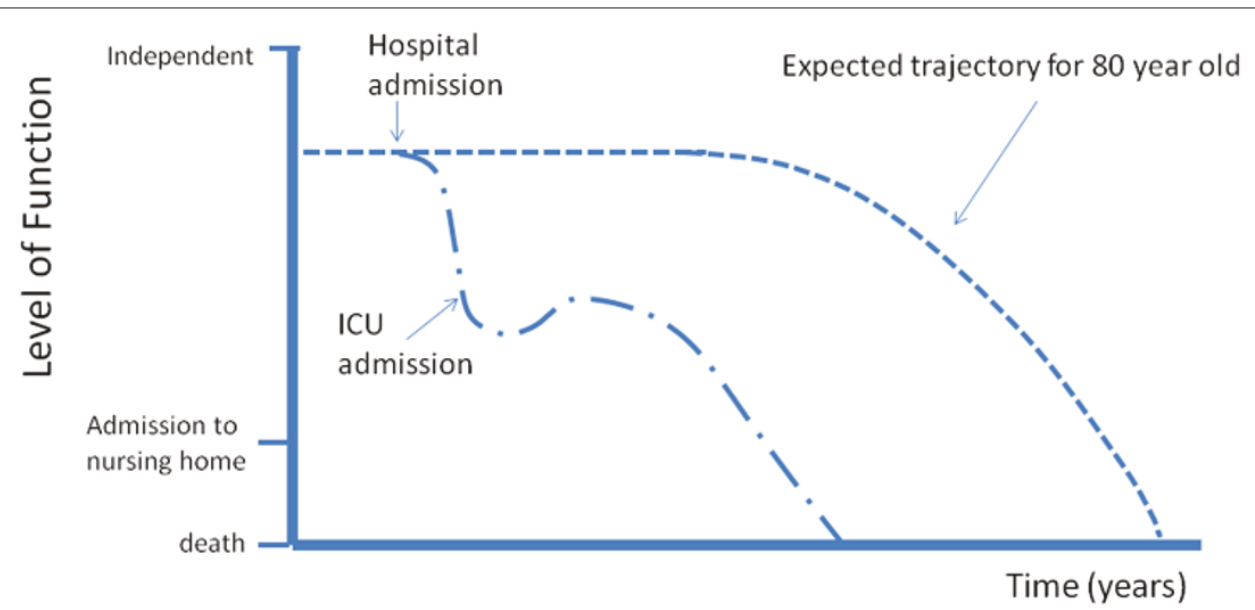

Figure 2. Expected trajectory of a patient for whom end-of-life care should be considered. The patient has a limited life expectancy due to age and ICU admission may be a major trigger for loss of independence and subsequent nursing home admission and progressive and more rapid decline. These possibilities need to be clearly and honestly discussed with patient and family as well as the primary clinician to develop a crisis response plan that is both patient-centered and realistic.

that the diagnosis of dying is either not formally considered or is delayed until an advanced stage in the course of the patient's illness. In the UK the percentage of patients dying in the ICU is much lower (approximately 6\%) [25], suggesting that this diagnosis is considered earlier and/or more commonly pursued outside the ICU, or that a lack of ICU resources and acute bed rationing leads to an inability to move some of these patients to the ICU, or both. In any of these scenarios, the social structure appears to affect the primary diagnosis of dying in hospital patients outside the ICU.

\section{The response to the diagnosis of dying}

Dying has powerful social and cultural features outside the above system-related aspects. Some cultures tend to be more pragmatic and accept death as a component of the lifecycle, as a good outcome under circumstances where quality of life is valued above quantity of life. In such cultures, the primary diagnosis of dying is sometimes perceived as helpful in preventing unnecessary, burdensome, painful, futile and undignified interventions. In other cultures, the prevention of death is seen as more important than the prevention of loss of dignity and quality of life. In these different cultural and social environments, doctors respond to dominant social attitudes [42-46].

There are also powerful psychological and family-based features to the diagnosis of dying $[47,48]$. They involve the expressed wishes of the patient (if known) and the psychological state of the family $[49,50]$. Loving individuals or families that have shared a common life-path have also often discussed these issues well, often have advance care directives and are more likely not only to accept the diagnosis of dying but also to report satisfaction with the outcome. On the contrary, families or individuals with the opposite psychological and social characteristics are more likely to dispute the diagnosis of dying and reject any alternative to active, technologybased intervention [2,23,51-53]. Once again, physicians respond to these psychological situations and pressures in their diagnostic approach.

However, clinical characteristics can remain compelling despite specific patient, family and physician social and psychological context. For example, the combined presence of a massive dominant hemispheric stroke, age $>80$, aspiration pneumonia, septic shock, acute renal failure and hypoxemic respiratory failure provide powerful and almost incontrovertible clinical evidence that the primary diagnosis is dying. In this patient, the brain computed tomography results together with blood lactate $>25 \mathrm{mmol} / \mathrm{l}$ and $\mathrm{pH} 6.98$ provide strong objective data that the patient's primary diagnosis is dying. Of course, the response to this still occurs within a valueladen context [51]. Although the primary diagnosis may not be disputed, a social context that emphasizes mere and unlikely survival over palliative care is likely to provide maximal technological support and defer the moment of death.

\section{Dying and key human values}

The primary diagnosis of dying also requires consideration to several related and value-based concepts. Although such concepts have a subjective quality and are impossible to quantify, they have value in social and medical discourse and need to be explicitly considered. These concepts are futility, dignity, and compassion. 


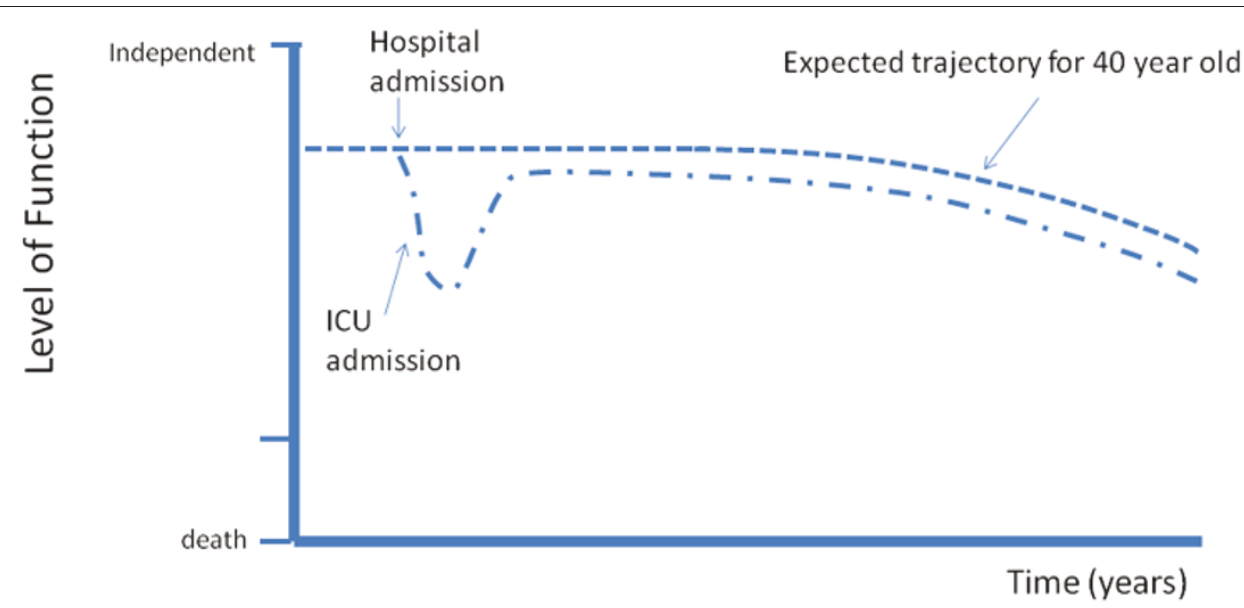

Figure 3. Expected trajectory of a patient when full treatment is considered during deterioration at hospital admission. The patient has decreased life expectancy due to combined effects of age, critical illness, and subsequent functional deterioration.

Futility refers to the concept that a given intervention will not result in the desired outcome [54]. Futility has multiple dimensions and is dynamic in nature, and the desired outcome similarly changes with time, person, perspective and response to intervention. Unsurprisingly, futility has been the subject of much debate in medicine [54] with both support for and antagonism towards it as a concept. Despite such controversy, the word is commonly used in medical conversations dealing with EOLC decisions and should be discussed when dying is a differential diagnosis.

Dignity is a similarly elusive concept with strong subjective components and yet is supported as useful by clinicians [55]. For many individuals, having an endotracheal tube, a urinary catheter, a rectal tube and being the subject of multiple invasive interventions is not an acceptable price for a few extra months of life, especially if its quality is poor. When asked, very few intensivists or intensive care nurses who understand these actions well and inflict them upon patients every day indicate they would be happy to receive such interventions unless the survival and quality-of-life gain was clear and likely.

Compassion is another key aspect of EOLC [56]. Compassion is an important key to the interpretation of futility and dignity and, when perceived to be present by the family, a major enabler of decision-making. Care must be explicitly given and seen to be given. As patients at risk of dying experience significant symptoms [57], a shift away from technology-based life-support systems must always be accompanied by an interventional plan that targets comfort, pain control, explanation, kindness, support, peace and understanding for both patient and family.

These key terms of futility, dignity and compassion when explored and specified in a particular clinical context, are important for determining whether dying is the primary diagnosis and its subsequent management. In the previous example of the 80 year old with hemispheric stroke, and sepsis with multiple organ failure, invasive organ support is technically possible and immediate death preventable. However, conferring an enduring benefit in terms of independent natural survival is statistically improbable, and attempts to do so are very likely to be associated with loss of dignity and suffering. When faced with this clinical scenario a compassionate stance is likely to result in the primary diagnosis of dying, with patient care directed towards the relief of suffering and preservation of dignity. Such consideration helps distinguish between what can be done (a technological decision limited by available resources) and what should be done (a moral decision shaped by the social and cultural context).

\section{Diagnostic uncertainty}

The concept of diagnostic uncertainty applies to the primary diagnosis of dying just as it does to any other medical diagnosis [58]. There is, however, a unique dimension to this uncertainty [59]. While the diagnosis of pneumonia may or may not be correct, the risk that true pneumonia will develop is never increased by its diagnosis. In contrast, the risk of dying is increased by the primary diagnosis of dying. This self-fulfilling prophecy effect requires caution in making the diagnosis of dying. Objective prognostic models for hospitalized patients [60] should be carefully applied, the limitations of these considered, and the consequences and degree of uncertainty of the diagnosis openly discussed [61]. Such uncertainty demands a careful discussion and consultation process with colleagues within the ICU and outside the ICU, a strong attempt to understand the patient's wishes, and a desire to, within reason, respect them. 
Respect for a patient's wishes and a family's wishes does not imply always, only and simply asking the family what to do. The ability of surrogate decision-makers to predict the patient's wishes may be just as limited as the doctor's ability to predict prognosis [62]. A surgeon cannot be made to operate on a patient who he/she feels will die anyway. An intensivist should not logically place a patient who he/she believes will die anyway on invasive mechanical ventilation: to do so appears misleading and unethical because it confers no enduring benefit and is not in the patient's best interests.

\section{Distributive justice}

The intensive care physician usually cares for many patients but physical and human resources are often limited. While it is unwise for the physician to make resource considerations his or her primary concern, it is not uncommon for intensivists to have to make decisions that are influenced by the availability of resources. The wise use of these resources requires consideration of distributive justice, an aspect of the dying process [63] that is not often appreciated. Primarily, it is important to identify the dying patient in the ICU or on the ward in order to change the focus of care from actual or potential technologic interventions to palliative care so that the patient's best interests can be served through the specific allocation of appropriate resources directed towards patient comfort. But, undeniably, a dying patient receiving futile treatment with therapeutic intent in the intensive care occupies and consumes a resource that cannot be made available to other patients. This may prevent, delay or dilute the allocation of intensive care resources to patients who may obtain a therapeutic enduring benefit from intensive care organ supports.

\section{Collegiality, family management and ICU team leadership}

The diagnosis of dying and its management is often extremely time consuming, emotionally burdensome and challenging. Such difficulties often impede consideration of the diagnosis of dying and implementation of an EOLC strategy. Negotiations with medical and/or surgical colleagues are often difficult. Primary physicians who have cared for a patient for many years are loath to let go. Intensivists should tackle such issues with openmindedness and, to a degree, welcome such advocacy. Some patients with the primary diagnosis of dying will die even though the primary physician insists on aggressive care; yet others will live even though the intensivist would have preferred EOLC. When such disagreement exists, collegiality, private discussions away from the bedside, courtesy, negotiation, involvement of senior colleagues from the same and/or different specialties, the setting of agreed indicators, and so forth, are all important means to achieve better identification and management of the dying process. Family discussions can be at least as challenging. Yet the same principles apply. Families typically respond to a physician who clearly wants to respect the patient's wishes, shows care and compassion, and yet guides the family to an understanding of why the diagnosis of dying is being considered and why it has now become the major relevant diagnosis. Although most patients are unable to participate in decision-making with regard to dying, when this is possible the patient's wishes should be considered, discussed and respected.

The diagnosis of dying also requires management of the ICU team, which also poses major challenges. ICU nurses and junior medical staff who have to care for a dying patient are often distressed by the length of the decisionmaking process and by prolongation of life in a setting where they feel the patient is suffering for no good reason [64]. They often wish to become involved in the decisionmaking process and to understand why particular decisions are made. In our unit nurses and junior medical staff often participate in family discussions. This helps in understanding the many and often conflicting issues involved, thereby providing comfort and understanding for the agreed meeting outcomes. Importantly, they are seen by the family to be part of a team effort directed towards the provision of best care.

After acceptance that dying is the primary relevant diagnosis, then a therapeutic transition should take place toward palliative care. However, such transition should not occur with undue haste as the dying patient and family should be treated with due respect. Adequate time should be provided for the family to be present at the bedside, adjust to the therapeutic transition and witness a peaceful death. The goal is to generate a recollection of the events that emphasizes understanding, peace and a sense of freedom from suffering. Of course all of these considerations may be seen as a series of commonsense statements, which is correct. But deliberate reflection on each of the above aspects of dying is helpful in providing better care. Increasingly, societies such as the Australian and New Zealand Intensive Care Society require advanced trainees to undertake formal training in these aspects of intensive care practice.

The above aspects and challenges of EOLC are now an established part of the daily lives of intensivists within the ICU, and in the hospital in general. However, another development is changing this landscape further in almost all English-speaking countries, in Scandinavian countries, in the Netherlands and in several hospitals in Europe and worldwide: the introduction of RRTs.

\section{Rapid response teams and end-of-life care}

There is an increasing trend for intensivists to respond and review patients who are deteriorating outside the 
ICU. Such review takes the form of RRTs, critical care outreach teams, and patient at-risk teams. RRTs are activated when patients fulfill objective criteria for deterioration that are typically based on derangements in vital signs (for example, blood pressure, respiratory rate, heart rate and conscious state) $[5,6]$.

RRTs evolved because of a variable and inconsistent recognition of ward patient deterioration, and the mismatch between the needs of deteriorating patients and available hospital ward resources. The original intent of RRTs was thus to prevent unplanned ICU admissions, serious adverse events, cardiac arrest and unexpected death $[5,6]$.

With expansion of these services to many hospitals, and with their increasing utilization within hospitals, there is emerging evidence that RRTs have become important in the provision of EOLC in hospital wards. This is perhaps not surprising, as patients at the end of life often display abnormalities in their vital signs. In some cases, ward doctors may not appreciate that the patient is dying, and advanced care directives may not be in place. In a 1-year study of 713 RRT calls, the RRTs determined that the patients should have been designated 'do not resuscitate' in $23 \%$ of calls [65]. In another study of 900 RRT patients, investigators found that $21.7 \%$ of such patients already had a documented do not resuscitate order [66].

In some cases of RRT review, the team members, in conjunction with the treating clinicians, form an opinion that the patient is not likely to benefit from cardiopulmonary resuscitation and/or intensive care therapies. In two single-center studies, the RRT members newly implemented limitations of medical therapy (LOMT) in $10 \%$ of RRT calls $[67,68]$.

A recent international prospective observational study specifically examined the role of the RRT in EOLC planning in seven hospitals. The study revealed that there were 652 RRT calls occurring in 518 patients during 1 month, of which $31.1 \%$ had LOMT [8]. Such LOMT orders were instituted in $20.3 \%$ of patients before and in $10.8 \%$ of patients after the RRT call, respectively. Compared with patients who did not have LOMT during the call, those with LOMT were older, were more likely to be admitted with a medical (rather than a surgical) condition and were less likely to be admitted from home. In addition, they were also less likely to be discharged home and were more likely to die in hospital. Calls in patients with LOMT tended to occur more often out of hours. Amongst the 78 patients who died with LOMT, the RRT call was most likely to occur on the day of their death ( $29.5 \%$ cases), with a further $28.2 \%$ having their last RRT call within 2 days of their death [8].

Combined these studies suggest that approximately one-third of RRT calls involve patients with an EOLC issue, and that one-tenth of calls involve the RRT implementing LOMT. The RRT therefore appears to be used as an intermittent agent for the provision of palliative care, and in one-tenth of cases appears to be essentially making the primary diagnosis of dying.

\section{Advantages and disadvantages of the rapid response team providing end-of-life care}

The RRT initially evolved because of a mismatch between the needs of deteriorating patients and the ward resources available to respond. The initial aim of this model of care was to identify, review and treat deteriorating patients in order to avoid preventable morbidity and mortality. The studies outlined above suggest that the RRT is frequently required to review ward patients who have urgent EOLC issues, and such reviews are requested urgently. This suggestion indicates a disparity between the resources on the ward to provide EOLC and the needs of the patients. These studies may also indicate a need for improved clarity of documentation by the parent medical team with respect to the extent and aggressiveness of medical interventions in deteriorating patients. A further interpretation of this data is that parent unit medical staff may not recognise dying patients or their ensuing EOLC needs. These aspects of EOLC increasingly involve intensivists and require investigation and improvement. Provision of prompt EOLC by the RRT probably prevents unnecessary suffering, distress or pain. In addition, 50\% of RRT patients with documented LOMT survive to hospital discharge, suggesting that the RRT is not purely palliating such patients. A single-center study revealed that introduction of a RRT resulted in improvement of EOLC in ward patients [69].

Despite the advantages of this approach, there are several disadvantages. First, the RRT may not know the patient, which may compromise the validity of EOL decisions. This compromise may result in conflict with the parent unit, or withholding of potentially beneficial therapy from the deteriorating patient [70]. However, a single-center study reported a high degree of concordance with decisions by the RRT and subsequent opinion of the treating team [71]. Second, the RRT may be the patient or family's first therapeutic encounter, thereby limiting rapport with RRT. A further problem is that many RRT EOLC calls occur out of hours when the parent unit may not be present. As the patient is often too unwell to participate in discussions, the calls often involve expedited decisions with the patient's family members and parent unit over the telephone. Such calls are stressful to families, parent units and RRT staff. The calls also remove staff from the ICU, often out of hours when medical staffing levels are lowest. These observations suggest that intensivists should be strong advocates for the widespread use of advance care 
directives in order to improve the quality of EOLC decisions.

\section{The importance of advanced care directives}

Although expedited provision of EOLC by the RRT is better than allowing a patient to suffer in discomfort, LOMT should ideally be documented prior to patient deterioration. This approach allows the patient to be informed of and involved in treatment options, as well as the potential burden/discomfort and likelihood of success for such therapies. With this approach, patient wishes and escalation plans could be clearly articulated to the arriving RRT when the patient deteriorates, avoiding unnecessary escalation in cases where palliation is indicated. A recent single-center randomized controlled trial assessed the effects of advanced care planning of EOLC for older patients [36]. Patients who received the intervention were more likely to have their end-of-life wishes known and followed than those in the control group. In addition, family members of the intervention group experienced less stress, anxiety and depression than those of the control patients. Importantly, patients in the intervention arm did not experience an increased mortality rate.

\section{Conclusion}

EOLC is a growing aspect of intensive care practice within the ICU, and now outside the ICU. Understanding the social, cultural and psychological dimensions of death should become part of the training for intensive care physicians. Formally considering the primary diagnosis of dying in all patients with critical illness either in the ICU or on the wards is also an important step toward delivering appropriate care and formulating a management plan that delivers outcomes that more closely satisfy individuals and families and avoid unnecessary suffering. The development of RRTs has added a new challenge in the field of such nosocomial EOLC by taking the intensivist's diagnosis of dying and its management to the general wards and requiring decisions to be made with more time constraints and less information. This development poses new challenges and requires training and reflection.

Finally, although there are a myriad of individual variations in the diagnosis and management of dying that make it, at times, more of an art than a science, there are also many universal aspects and values that can and should be studied using scientific methodology and controlled trials. We owe it our patients, their families, our colleagues and ourselves to conduct such studies, however difficult they might prove. There is one more reason to do this: the future will deliver even more of these challenges as the population ages, the organ-support technology advances, costs escalate, the resources available to pay for them proportionally diminish, the quality and quantity of life gained with aggressive intervention directed at preserving life decrease, and society is faced with an epidemic of older patients with dementia. As the custodians of this technology, we must be prepared for these challenges and educate the community to be prepared for them as well. Nosocomial thanatology will only become a bigger and more complex component of intensive care medicine in the future.

\section{Abbreviations}

EOLC, end of life care; LOMT, limitations of medical therapy; RRT, rapid response team.

\section{Competing interests}

The authors declare they have no competing interests.

\section{Author details}

'Department of Intensive Care, Alfred Hospital, Prahran, Victoria 3181, Australia. ${ }^{2}$ Australian and New Zealand Intensive Care - Research Centre, School of Public Health and Preventive Medicine, Monash University, Alfred Hospital Campus, Commercial Road, Prahran, Victoria 3181, Australia.

Published: 26 April 2013

\section{References}

1. Zamperetti N, Bellomo R, Defanti CA, Latronico N: Irreversible apneic coma 35 years later. Towards a more rigorous definition of brain death? Intensive Care Med 2004, 30:1715-1722.

2. Luce JM: End of life decision making in the intensive care unit. Am J Respir Crit Care Med 2010, 182:6-11.

3. Sprung CL, Ledoux D, Bulow HH, Lippert A, Wennberg E, Baras M, Ricou B, Sjikvist P, Wallis C, Maia P, Thijs LG. Solsona Duaran J; Ethicus Group: Relieving suffering or intentionally hastening death: where do you draw the line? Crit Care Med 2008, 36:8-13.

4. Cook DJ, Giacomini M, Johnson N, Wilms D: Life support in the intensive care unit: a qualitative investigation of technological purposes. CMAJ 1999, 161:1109-1113.

5. Jones DA, DeVita M, Bellomo R: Current concepts: rapid-response teams. N Engl J Med 2011, 365:139-146.

6. DeVita MA, Bellomo R, Hillman K, Kellum J, Rotondi A, Teres D, Auerbach A Chen WJ, Duncan K, Kenward G, Bell M, Buist M, Chen J, Bion J, Kirby A, Lighthall G, Overvreit J, Braithwaite RS, Gosbee J, Millbrandt E, Peberdy M, Savitz L, Young L, Harvey M, Galhotra S: Findings of the first consensus conference on medical emergency teams. Crit Care Med 2006, 34:2463-2478

7. Vetro J, Natarajan DK, Mercer I, Buckmaster JN, Heland M, Hart GK, Bellomo R, Jones DA: Antecedents to cardiac arrest in a hospital equipped with a medical emergency team. Crit Care Resusc 2011, 13:162-166.

8. Jones DA, Bagshaw S, Barrett J, Bellomo R, Bhatia G, Bucknall TK, Casamento AJ, Duke GJ, Gibney N, Hart GK, Hillman KM, Jaderling G, Parmar A, Parr MJ: The role of the medical emergency team in end-of-life care: a multicenter, prospective, observational study. Crit Care Med 2012, 40:98-103.

9. Knott Cl, Psirides AJ, Young PJ, Sim D: A retrospective cohort study of the effects of medical emergency teams on documentation of advance care directives. Crit Care Resusc 2011, 13:167-174.

10. Simmes GM, Schoonhoven L, Mintjes J, Fikkers BG, van der Hoeven JG: Incidence of cardiac arrests and unexpected deaths in surgical patients before and after implementation of a rapid response system. Ann Intensive Care 2012, 2:20-26

11. Trinkle RM, Flabouris A: Medical reviews before cardiac arrest, medical emergency call or unanticipated intensive care unit admission: their nature and impact on patient outcome. Crit Care Resusc 2011, 13:175-180.

12. Konrad D: MET: an intensive care (r)evolution. Strong medical and ethical reasons for introducing a mobile emergency team. Lakartidningen 2006, 103:3594-3595.

13. Cheung W, Aggarwal G, Fugaccia E, Thanakrishnan G, Milliss D, Anderson R, Stock D, Bird H, Tan J, Fryc AC: Palliative care teams in the intensive care 
unit: a randomised controlled feasibility trial. Crit Care Resusc 2010, 12:28-35.

14. Lafrenz T, Lindberg SO, LaCour JL, Folkestad L, Hallas P, Brabrand M: Emergency teams in Danish emergency departments. Dan Med J 2012, 59:A4451

15. Jones S, Mullaly M, Ingleby S, Buist M, Bailey M, Eddleston JM: Bedside electronic capture of clinical observations and automated clinical alerts to improve compliance with an early warning score protocol. Crit Care ResusC 2011, 13:83-88

16. Bellomo R, Ackerman M, Bailey M, Beale R, Clancy G, Danesh V, Hvarfner A, Jimenez E, Konrad D, Lecardo M, Pattee KS, Ritchie J, Sherman K, Tangkau P. VITAL Study Investigatros: A controlled trial of electronic automated advisory vital signs monitoring in general hospital wards. Crit Care Med 2012, 4:2349-2361.

17. Frost S, Davidson PM, Alexandrou E, Hunt L, Salamonson Y, Tam V, Parr MJ, Aneman A, Hillman KM: Unplanned admission to the intensive care unit in the very elderly and risk of in-hospital mortality. Crit Care Resusc 2010 12:171-176.

18. Gibbins J, McCoubrie R, Alexander N, Kinzel C, Forbes K: Diagnosing dying in the acute hospital setting - are we too late ? Clin Med 2009, 9:116-118.

19. Glare P, Virik K, Jones M, Hudson M, Eychmuller S, Simes J, Christakis N: A systematic review of physicians' survival prediction in terminally ill cancer patients. BMJ 2003, 327:195-201.

20. Finucane TE: How gravely ill becomes dying - a key to end-of-life care JAMA 1999, 282:1670-1672.

21. SUPPORT Investigators: A controlled trial to improve care for seriously ill hospitalized patients. The study to understand prognosis and preferences for outcomes and risks of treatment. JAMA 1995, 274:1591-1598.

22. Pulchalski CM, Zhong Z, Jacobs MM, Fox E, Lynn J, Harrold J, Galanos A, Phillips RS, Califf R, Teno JM: Patients who want their families and physician to make resuscitation decisions for them: observations from the SUPPORT and HELP study to understand prognoses and preferences for outcomes and risk of treatment. Hospitalized elderly longitudinal project. J Am Geriatr Soc 2000, 48(Suppl 5):S84-S90

23. Luce JM: A history of resolving conflicts over end-of-life care in intensive care units in the United States. Crit Care Med 2010, 38:1623-1629.

24. Angus DC, Barnato AE, Linde-Zwirble WT, Weissfeld LA, Watson RS, Rickert T, Rubenfeld GD: Use of intensive care at the end of life in the United States: an epidemiologic study. Crit Care Med 2004, 32:638-643.

25. Wunsch $H$, Linde-Zwirble WT, Harrison DA, Barnato AE, Rowan KM, Angus DC Use of intensive care services during terminal hospitalisations in England and the United States. Am J Respir Crit Care Med 2009, 180:875-880.

26. Wunsch $H$, Angus DC, Harrison DA, Collange O, Fowler R, Hoste AE, de Keize NF, Kersten A, Linde-Zwirble WT, Sandiumenge A, Rowan KM: Variation in critical care services across North America and Western Europe. Crit Care Med 2008, 36:2787-2793.

27. Sprung C, Cohen SL, Sjokvist P, Baras M, Bulow HH, Hovilehta S, Ledoux D, Lippert A, maia P, Phelan D, Schobersberger W, Wennberg E, WoodcockT; Ethicus Study Group: End-of-life practices in European intensive care units - the Ethicus study. JAMA 2003, 290:790-796.

28. Brieva IL, Cooray P, Rowley M: Withholding and withdrawal of lifesustaining therapies in intensive care: an Australian experience. Crit Care Resusc 2009, 11:266-268.

29. Gavrin JR: Ethical consideration at the end of life in the intensive care unit Crit Care Med 2007, 35(Suppl):S85-S94

30. Azoulay E, Metnitz B, Sprung CL, Timsit JF, Lemaire F, Bauer P, Schlemmer B, Moreno R, Metnitz P; SAPS 3 Investigatros: End-of-life practices in 282 intensive care units: data from the SAPS III database. Intensive Care Med 2009, 35:623-630.

31. Truog RD, Campbell ML, Curtis JR, Haas CE, Luce JM, Rubenfeld GD, Rushton $\mathrm{CH}$, Kaufman DC: Recommendations for end of life care in the intensive care unit: a consensus statement by the American Academy of Critical Care Medicine. Crit Care Med 2008, 36:953-963.

32. Powner DJ, Ackerman BM, Grenvik A: Medical diagnosis of death in adults: historical contributions to current controversies. Lancet 1996 348:1219-1223.

33. Randall Curtis J, Vincent JL: Ethics and end-of-life care for adults in the intensive care unit. Lancet 2010, 375:1347-1353.

34. Silvester W, Detering KM: Advance directives, perioperative care and endof-life planning. Best Prac Res Clin Anaesthesiol 2011, 25:451-460.

35. Steinhauser KE, Clipp EC, McNeilly M, Christakis NA, McIntyre LM, Tulsky JA: In search of a good death: observations of patients, families and providers Ann Intern Med 2000, 132:825-832.

36. Detering KM, Hancock AD, Reade MC, Silvester W: The impact of advance care planning on end of life care in elderly patients: a randomized controlled trial. BMJ 2010, 340:c1345.

37. Cohen J, Houttekier D, Onwuteaka-Philpsen B, Deliens L: Which patients with cancer die at home? A study of six European countries using death certificate data. J Clin Oncol 2010, 28:2267-2273.

38. Rosenwax LK, McNamara BA, Murray K, McCabe RJ, Aoun SM, Currow DC: Hospital and emergency department use in the last year of life: a baseline for future modifications to end of life care. Med J Aust 2011, 194:570-573.

39. Ellershaw J, Ward C: Care of the dying patient: the last hours or days of life. BMJ 2003, 326:30-34.

40. Corke CF, Lavery JF, Gibson AM: Choosing life support for suddenly severely ill elderly relatives. Crit Care Resusc 2005, 7:81-85.

41. Corke C, Silvester W, Bellomo R: Avoiding nosocomial dysthanasia and promoting eleothanasia. Crit Care Resusc 2010, 12:221-222

42. Ehlenbach WJ, Barnato AE, Curtis JR, Kreuter W, Koepsell TD, Deyo RA Stapelton RD: Epidemiologic study of in-hospital cardiopulmonary resuscitation in the elderly. N Engl J Med 2009, 361:22-31.

43. Diem SJ, Lantos JD, Tulsky JA: Cardiopulmonary resuscitation on television. Miracles and misinformation. N Engl J Med 1996, 334:1578-1582.

44. Fried TR, Bradley EH, Towle VR, Allore H: Understanding the treatment preferences of seriously ill patients. N Engl J Med 2002, 346:1061-1066.

45. Sprung CL, Carmel S, Sjokvist P, Baras M, Cohen SL, Maia P, Beishuizen A, Nalos D, Novak I, Svantesson M, Benbenishty J, Henderson B; ETHICATT Study Group: Attitudes of European physicians, nurses, patients, and families regarding end of life decisions: the ETHICATT study. Intensive Care Med 2007, 33:104-110.

46. Fidler H, Thompson C, Freeman A, Hogan D, Walker G, Weinman J: Barriers to implementing a policy not to attempt resuscitation in acute medical admissions: prospective, cross sectional study of successive cohort. BM 2006, 332:461-462

47. Reigner J, Dumont R, Katsahian S, Martin-Lefevre L, renard B, Fiancette M, Lebert C, Clementi E, Bontemps F: Patient-related factors and circumstances surrounding decisions to forego life-sustaining treatment including intensive care unit admission refusal. Crit Care Med 2008, 36:2076-2083.

48. Nelson JE, Puntillo KA, Pronovost PJ, Walker AS, McAdam JL:, Ilaoa D, Penrod J: In their own words: patients and families define high-quality palliative care in the intensive care unit. Crit Care Med 2010, 38:808-818.

49. Camhi SL, Mercado AF, Morrison S, Du Q, Platt DM, August GI, Nelson JE: Deciding in the dark: advance directives and continuation of treatment in chronic critical illness. Crit Care Med 2009, 37:919-925.

50. McAdam JL, Dracup KA, White DB, Fontaine DK, Puntillo KA: Symptom experiences of family members of intensive care unit patients at high risk of dying. Crit Care Med 2010, 38:1078-1085.

51. Johnson SK, Bautista CA, Hong SY, Weissfeld L, White DB: An empirical study of surrogates' preferred level of control over value-laden life support decisions in intensive care units. Am J Respir Crit Care Med 2011, 183:915-921.

52. Boyd EA, Lo B, Evans LR, Malvar G, Apatira L, Luce JM, White DB: It's not just what the doctor tells me': factors that influence surrogate decisionmakers' perceptions of prognosis. Crit Care Med 2010, 38:1270-1275.

53. Zier LS, Burack JH, Micco G, Chipman AK, Frank JA, Luce JM, White DB: Doubt and belief in physicians' ability to prognosticate during critical illness: the perspective of surrogate decision makers. Crit Care Med 2008 36:2341-2347.

54. Schneiderman $\sqcup$, Jecker NS, Jonsen AR: Medical futility: its meaning and ethical implications. Ann Intern Med 1990, 112:949-954.

55. Antiel RM, Curlin FA, James KM, Sumasy DP, Tilburt JC: Dignity in end-of-life care: results of a national survey of US physicians. J Pain Symptom Manage 2012. [Epub ahead of print]

56. Halifax J: A heuristic model of enactive compassion. Curr Opin Support Palliat Care 2012, 6:228-235.

57. Puntillo KA, Arai S, Cohen NH, Gropper MA, Neuhaus J, Paul SM, Miaskowski C: Symptoms experienced by intensive care unit patients at high risk of dying. Crit Care Med 2010, 38:2155-2160

58. McKechnie R, MaaLeod R, Keeling S: Facing uncertainty: the lived experience of palliative care. Palliat Support Care 2007, 5:367-376

59. Fisher M, Ridley S: Uncertainty in end of life care and shared decision 
making. Crit Care Resusc 2012, 14:81-87.

60. Duke GJ, Graco M, Santamaria J, Shann F: Validation of the hospital outcome prediction equation (HOPE) model for monitoring clinical performance. Intern Med J 2009, 39:283-289.

61. Rocker G, Cook D, Sjokvist P, Weaver B, Finfer S, McDonald E, Marshall J, Kirby A, Levy M, Dodek P, Heyland D, Guyatt G: Clinician predictions of intensive care unit mortality. Crit Care Med 2004, 32:1149-1154.

62. Shalowitz DJ, Garret-Meyer E, Wendler D: The accuracy of surrogate decision makers: a systematic review. Arch Intern Med 2006, 166:493-497.

63. Pronovost $\mathrm{P}$, Angus DC: Economics of end of life care in the intensive care unit. Crit Care Med 2001, 29(2 Suppl):N46-N51.

64. Hamric AB, Blackhall $L$ : Nurse-physician perspectives on the care of dying patients in the intensive care units: collaboration, moral distress and ethical climate. Crit Care Med 2007, 35:422-429.

65. Parr MJ, Hadfield JH, Flabouris A, Bishop G, Hillman K: The Medical Emergency Team: 12 month analysis of reasons for activation, immediate outcome and not-for-resuscitation orders. Resuscitation 2001, 50:39-44.

66. Calzavacca P, Licari E, Tee A, Mercer I, Haase M, Haase-Fielitz A, Jones D, Gutteridge G, Bellomo R: Features and outcome of patients receiving multiple Medical Emergency Team reviews. Resuscitation 2010, 81:1509-1515.
67. Buist MD, Moore GE, Bernard SA, Waxman BP, Anderson JN, Nguyen TV: Effects of a medical emergency team on reduction of incidence of and mortality from unexpected cardiac arrests in hospital: preliminary study. BMJ 2002, 324:387-390

68. Casamento AJ, Dunlop C, Jones DA, Duke G: Improving the documentation of Medical Emergency Team Reviews. Crit Care Resusc 2008, 10:24-29.

69. Vazqruez R, Gheorghe C, Grigoriyan A, Palvinskaya T, Amoateng-Adjepong Y, Manthous CA: Enhanced end-of-life care associated with deploying a rapid response team: a pilot study. J Hosp Med 2009, 4:449-452.

70. Joyce C, McArthur C: Rapid response systems: have we MET the need? Crit Care Resusc 2007, 9:127-128.

71. Micallef S, Skrifvars MB, Parr MJ: Level of agreement on resuscitation decisions among hospital specialists and barriers for documenting do not attempt resuscitation (DNAR) orders in ward patients. Resuscitation 2011, 82:815-818.

\section{doi:10.1186/cc11856}

Cite this article as: Hilton AK, et al: Clinical review: The role of the intensivist and the rapid response team in nosocomial end-of-life care. Critical Care $2013,17: 224$ 


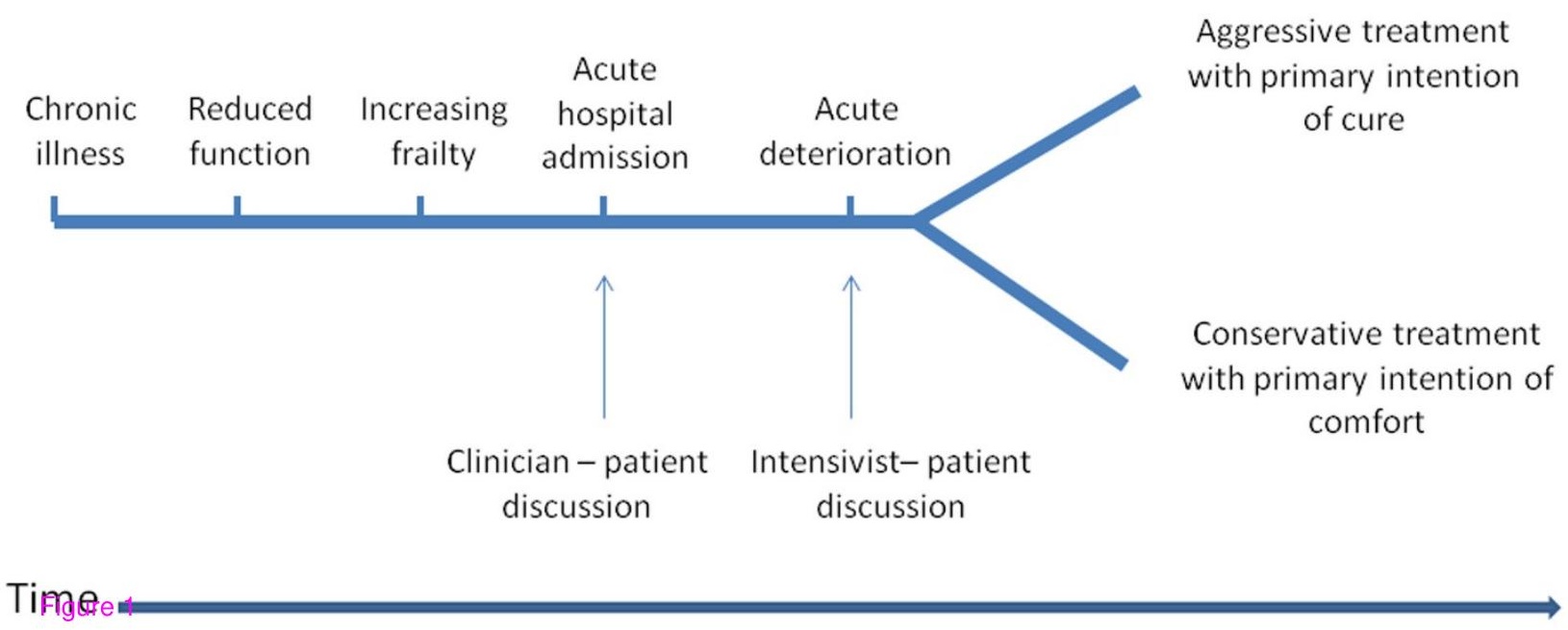




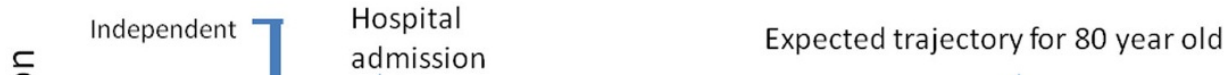
death 
